SCIENCE CHINA
Physics, Mechanics \& Astronomy

- Article •
July 2016 Vol. 59 No. 7: 674611

doi: 10.1007/s11433-016-0098-2

\title{
A comparative analysis of reticular crack on ceramic plate driven by thermal shock
}

\author{
XiangHong $\mathrm{Xu}^{*}$, ShiLong Sheng, Cheng Tian, and WenJun Yuan \\ State Key Laboratory of Nonlinear Mechanics (LNM), Institute of Mechanics, Chinese Academy of Sciences, Beijing 100190, China
}

Received March 11, 2016; accepted April 5, 2016; published online May 24, 2016

\begin{abstract}
Reticular crack is generally found on the surface of ceramic material that has been subjected to a thermal-shock condition. In the present study, a quantitative effect of thermal shock and quench temperature has been studied and investigated. Experimental tests were carried out to characterize the reticular crack that has been found in the Ge Kiln, which is a famous art of the ancient Chinese culture. After comparative analysis between thermal-shock cracks and the glaze crack patterns of the Ge Kiln porcelain, it is found that this study is expected to provide a powerful tool for recurrence of the long-lost firing and cooling process of the Ge Kiln porcelain.
\end{abstract}

reticular crack, thermal shock, ceramics, Ge Kiln porcelain

PACS number(s): 62.20.Mk, 81.05.Je, 65.40.De

Citation: X. H. Xu, S. L. Sheng, C. Tian, and W. J. Yuan, A comparative analysis of reticular crack on ceramic plate driven by thermal shock, Sci. China-Phys. Mech. Astron. 59, 674611 (2016), doi: 10.1007/s11433-016-0098-2

\section{Introduction}

Thermal stresses due to the change of environmental temperature could cause fatal defect or even failure of ceramics, that is one of the terrible factors to restrict the applications of ceramics $[1,2]$. When ceramics are subjected to a sudden change in the environmental temperature, i.e., thermal shock, a stress intensification resulted from the temperature gradient along the heat flow axis is formed and the surface of ceramics is one of the most vulnerable parts of material [3]. Once the thermal stress on the ceramic surface reaches a critical value, the most probable cracks formed on the heat-transfer surface are reticular-shaped cracks. Usually, reticular crack is a typical cracking way of brittle materials, which includes cracking of mud [4], paint [5,6], glass [7], battery [8], thermal-barrier coatings $[9,10]$, ancient-porcelain glaze [11], etc.

*Corresponding author (email: xxh@1nm.imech.ac.cn)
Various reticular-crack patterns are found in these cracking phenomena under different conditions. It is important to investigate the formation mechanisms and the characterization for the reticular crack in brittle materials $[12,13]$. This cannot only prevent the occurrence of crack in brittle materials, but also control and design the appearance of reticular crack in order to serve for human. For example, through controlling cracking process, cracking glaze of ancient porcelain made the Ge Kiln, one of the five major ceramics kilns in the Song Dynasty, with a unique beauty. Wang et al. $[14,15]$ designed an experimental platform to realize the in-situ observation during the thermal shock experiments. Experimental results show that all the cracks initiate from one of the edge midpoints and propagate to another one for square specimens. Furthermore, the crack arrest in brittle ceramics during thermal shock and ablation was reported. In the experiment, the specimens of $\mathrm{Al}_{2} \mathrm{O}_{3}$ are subjected to oxygen-propane flame heating until the temperature arises up to $1046^{\circ} \mathrm{C}$ and then 
are cooled down in air. The crack occurs, however, it does not propagate when arrested by the microstructures (e.g., micro-bridges) of the crack tip. Xu et al. [16] conducted experimental analysis of the cracking in the ceramics subsequent to water quenching to clarify the uncertainties of cracking in the ceramics when subjected to thermal shock. The results here indicate that at the critical point of quench temperature, the crack density and the depth reached the minimum and the maximum limits, respectively.

In this study, the reticular cracks on the ceramic plate after thermal shock are found and characterized quantitatively. The effect of quench temperature on the reticular cracks has been characterized and quantitatively separated. And a comparative investigation between the cracked glaze of the porcelain in the Ge Kiln and the reticular crack pattern on ceramic plate surface is expected to provide a clue for the long-lost preparing process of the Ge Kiln.

\section{Experimental procedure}

Commercially available $\mathrm{Al}_{2} \mathrm{O}_{3}$ powder (particle size $0.5 \mu \mathrm{m}$, purity $99.5 \%$ ) was pressed at $20 \mathrm{MPa}$, and subsequently sintered at $1650^{\circ} \mathrm{C}$ for $2 \mathrm{~h}$ at normal pressure to form a plate with the dimension of $50 \mathrm{~mm} \times 50 \mathrm{~mm} \times 10 \mathrm{~mm}$. The porosity of the sintered sample is about $4 \%$, and the mean grain size is about $10 \mu \mathrm{m}$. The ceramic plates used for thermal-shock test were ground, polished, and slightly chamfered to remove the machining defects (Figure 1).

The plates were initially heated to a preset quench tempera-

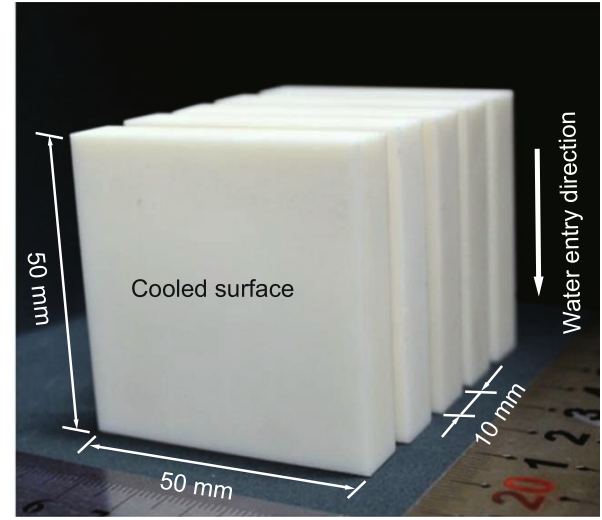

Figure 1 (Color online) $\mathrm{Al}_{2} \mathrm{O}_{3}$ ceramic plates prepared for thermal shock test. The cooled surface refers to the area of $50 \mathrm{~mm} \times 50 \mathrm{~mm}$, and the arrow indicates the water entry direction.

ture in a muffle furnace, and then held for 20 min to reach a thermal equilibrium. After that, the plates were immersed into water with a room temperature of $17^{\circ} \mathrm{C}$. The quench temperature ranged from $200^{\circ} \mathrm{C}$ to $800^{\circ} \mathrm{C}$, with the minimum temperature interval of $10^{\circ} \mathrm{C}$. After drying and then dying in blue ink, the crack patterns in a region of $50 \mathrm{~mm} \times 50 \mathrm{~mm}$ on the cooled surface were photographed by a digital scanner (Figure 2). After that, perpendicular to the cooled surface, the plates were cut into bars with dimensions of $50 \mathrm{~mm} \times 10$ $\mathrm{mm} \times 5 \mathrm{~mm}$ (Figure 3 ). Through comparing the crack patterns before and after cutting, it can be seen that the cutting process has little effect on the existing crack. The cracks on the cut surface, $50 \mathrm{~mm} \times 10 \mathrm{~mm}$, were observed by the same method (Figure 4).
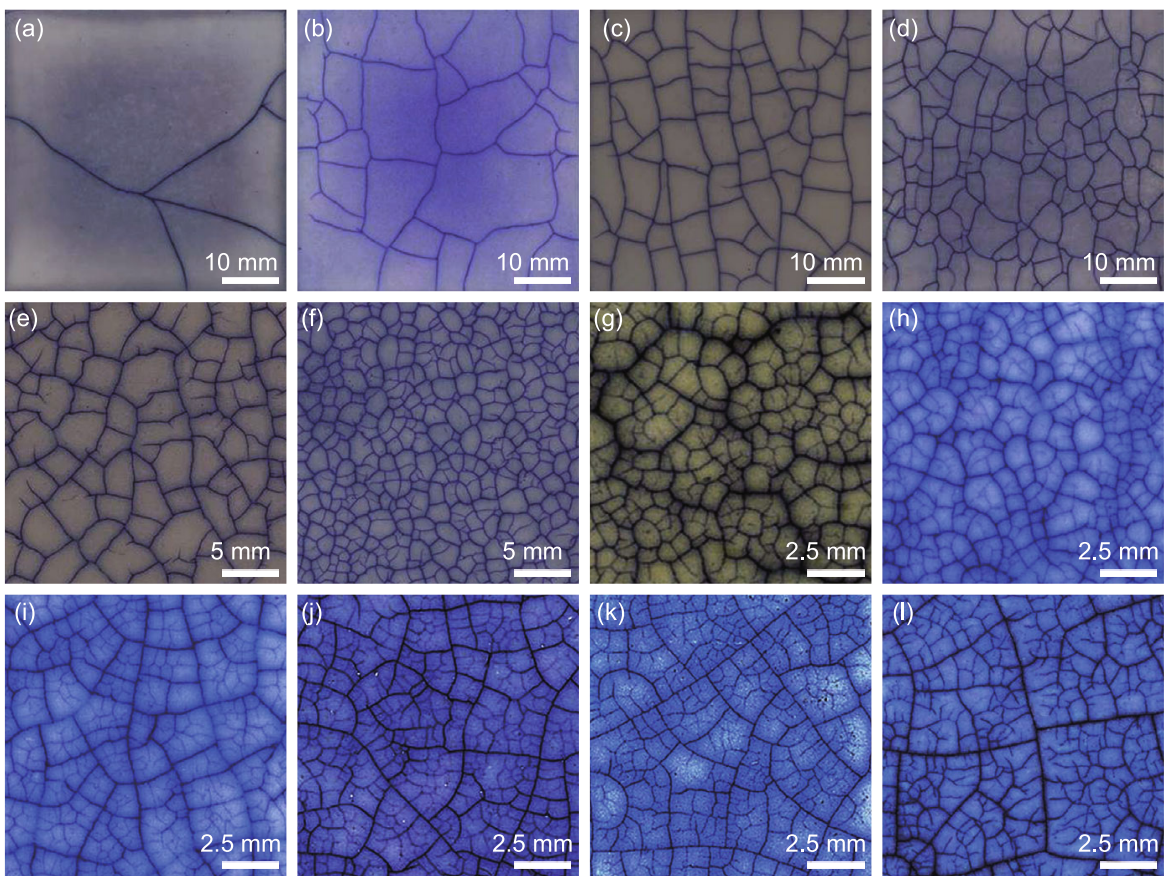

Figure 2 (Color online) Thermal shock cracks on the cooled surface of the ceramic plates quenched in water at $17^{\circ} \mathrm{C}$. The quench temperature $T$ is $(\mathrm{a}) 200^{\circ} \mathrm{C}$; (b) $210^{\circ} \mathrm{C}$; (c) $240^{\circ} \mathrm{C}$; (d) $260^{\circ} \mathrm{C}$; (e) $280^{\circ} \mathrm{C}$; (f) $290^{\circ} \mathrm{C}$; (g) $300^{\circ} \mathrm{C}$; (h) $400^{\circ} \mathrm{C}$; (i) $500^{\circ} \mathrm{C}$; (j) $600^{\circ} \mathrm{C}$; (k) $700^{\circ} \mathrm{C}$; (1) $800^{\circ} \mathrm{C}$. 


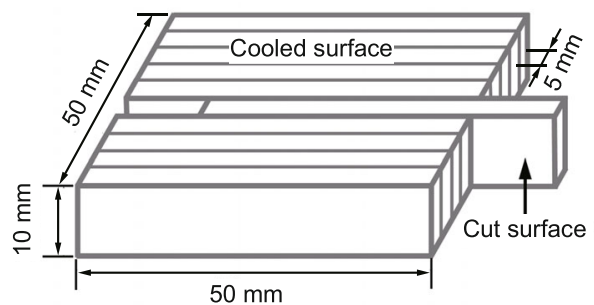

Figure 3 Cutting methods of ceramic plates. The cut surface refers to the area of $50 \mathrm{~mm} \times 10 \mathrm{~mm}$.

\section{Characterization of reticular cracks}

In the water quenching test, the surface of the ceramic plate directly contacts to the water, which causes the network-formed crack induced by thermal shock on the cooled surface (Figure 2). No cracking was detected at the quench temperature of $T<200^{\circ} \mathrm{C}$. However, cracking was detected at the higher temperature than $200^{\circ} \mathrm{C}$. The critical temperature, $T_{\mathrm{c}}$, suggested the first thermal-shock crack occurred at $200^{\circ} \mathrm{C}$. As $T$ increases, the evolution of the thermal-shock reticular cracks exhibits two main features: the increment of density and the change of the crack thickness.

The reticular cracks on the cooled surface present a hierarchical structure for the thick and fine cracks as the quench temperature increases. Correspondingly, the cracks on the cut surface display a hierarchical structure for the long and short cracks. Generally speaking, thick cracks are deep, while thin cracks are relatively shallow. Through comparative analysis of thermal-shock cracks on the cooled surface and those inside the sample, it is clear that the thickness of the reticular crack on the cooled surface corresponds to the depth of the crack on the cut surface. In other words, the thick cracks on the cooled surface correspond to the long cracks on the cut surface, and vice versa (Figure 4). Therefore, the characteristic of the reticular cracks thickness on the cooled surface with quench temperature has been represented by the depth of the cracks on the cut surface. The maximum vertical distance from the tip of a crack to the side was defined as crack depth and its dimensionless expression was obtained by dividing by half of the sample height $(5 \mathrm{~mm})$. Using the group average method [17], the cracks with length grading structure can be divided into long cracks and short cracks with depth greater and lesser than 0.39 , respectively. The statistical distribution and mean value of the crack depth on the cut surface versus quench temperature are shown in Figures 5 and 6(a), respectively, excluding the data as $T>500^{\circ} \mathrm{C}$ since the cracks on the cut surface are connected to one another and cover the entire section.

Moreover, the density of the reticular cracks also changes with the quench temperature. To characterize the density of the reticular cracks, crack density on the cut surface and crack
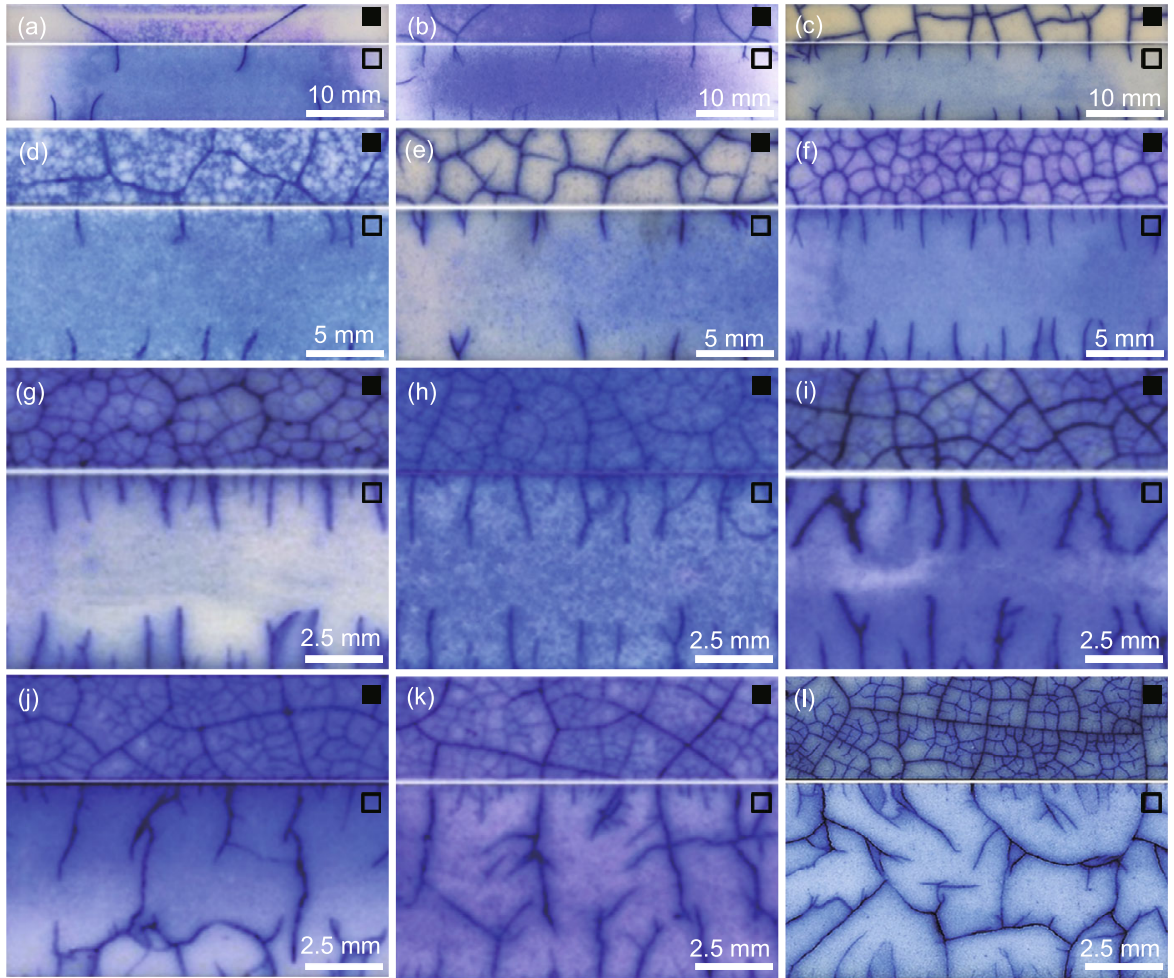

Figure 4 (Color online) Thermal shock cracks on the cut surface (wide strips indicated by solid squares $\mathbf{\square}$ ) and the cooled surface (narrow strips indicated by hollow squares $\square$ ) of the ceramic plates quenched in water at $17^{\circ} \mathrm{C}$. The quench temperature is (a) $200^{\circ} \mathrm{C}$; (b) $210^{\circ} \mathrm{C}$; (c) $240^{\circ} \mathrm{C}$; (d) $260^{\circ} \mathrm{C}$; (e) $280^{\circ} \mathrm{C}$; (f) $290^{\circ} \mathrm{C}$; (g) $300^{\circ} \mathrm{C}$; (h) $400^{\circ} \mathrm{C}$; (i) $500^{\circ} \mathrm{C}$; (j) $600^{\circ} \mathrm{C}$; (k) $700^{\circ} \mathrm{C}$; (1) $800^{\circ} \mathrm{C}$. 


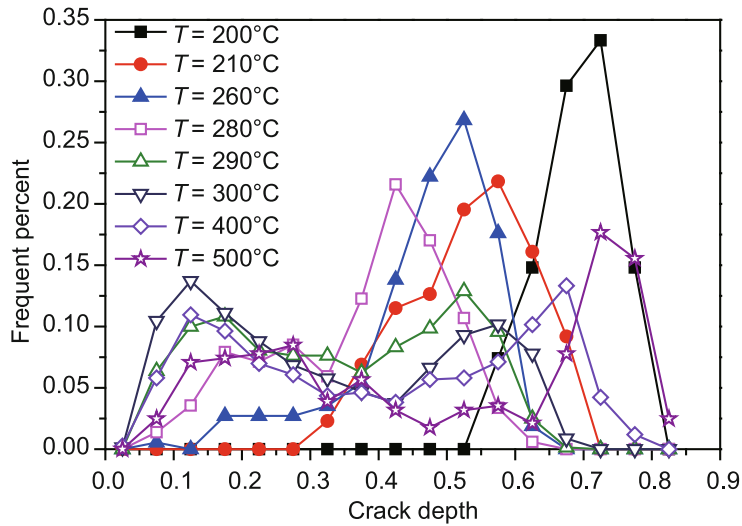

Figure 5 (Color online) Statistical distribution of the crack depth on the cut surface.

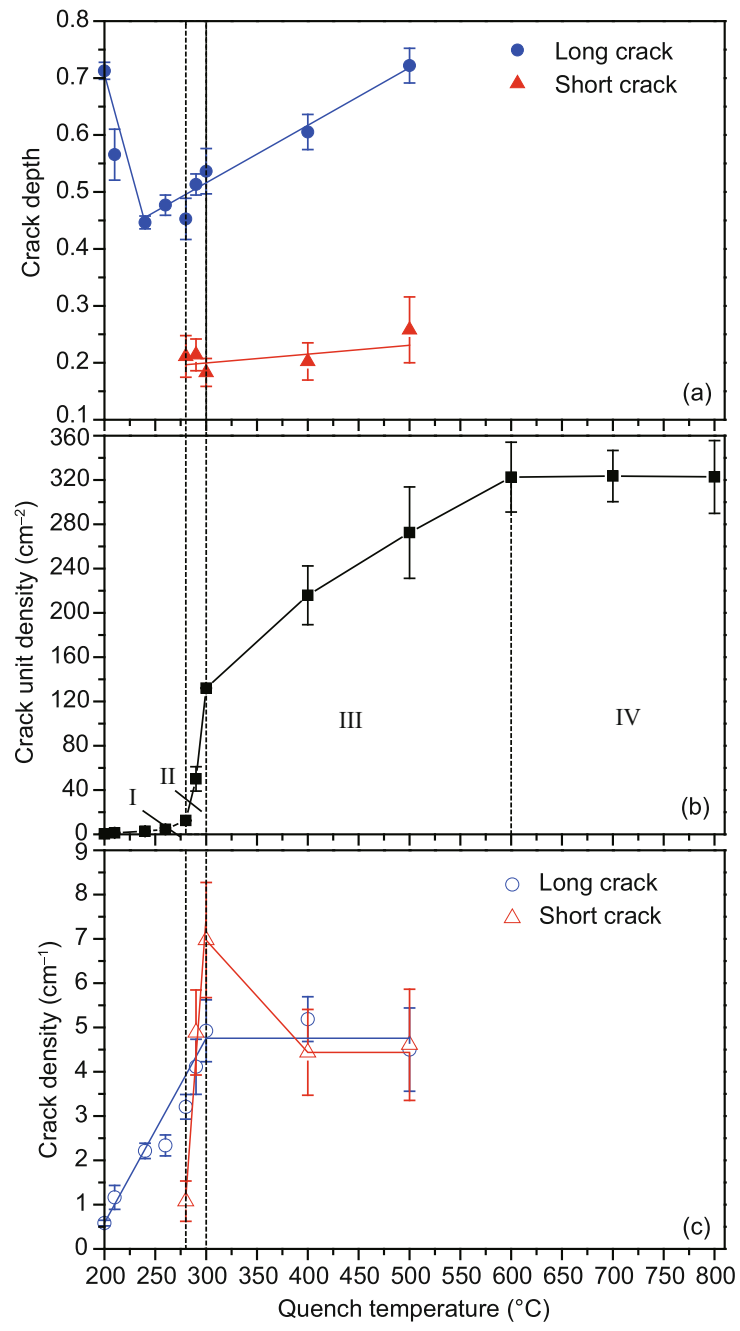

Figure 6 (Color online) Characterization parameters of thermal shock cracks versus quench temperature. The values are the statistical averaged from five samples. (a) Crack depth on the cut surface; (b) crack unit density on the cooled surface; (c) crack density on the cut surface.

unit density on the cooled surface are adopted. On the cut surface, crack density is defined as the number of cracks per unit length along the lengthwise direction. On the cooled surface, crack unit is defined as the single domain enclosed by cracks and indicated by the arrows in Figure 7. In statistical process, the sample boundary is considered as the partial boundary of crack unit, as indicated by the black arrow in Figure 7, thus this crack unit is enclosed by both the sample boundary and cracks. When suffered dangling crack, as indicated by the arrows in Figure 8, a straight line at the crack tip, B, along the tangential direction is plotted intersecting with the nearest crack at $\mathrm{C}$, as indicated by the dotted line in Figure 8. If the distance of $\mathrm{BC}$ is less than the half distance of $\mathrm{AC}$, the dangling crack is retained (the black arrow in Figure 8); otherwise, it is removed (the white arrow in Figure 8). Moreover, the overall statistics are conducted as the quench temperature $T \leqslant 280^{\circ} \mathrm{C}$, while the sampling statistics are conducted as $T>280^{\circ} \mathrm{C}$. In the square statistic regions selected randomly in

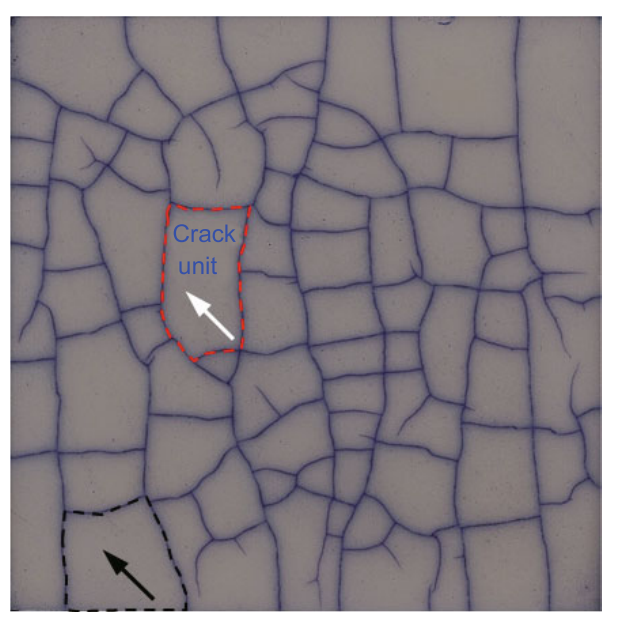

Figure 7 (Color online) Schematic of crack unit. The area surrounded by the dashed line refers to a crack unit. The one indicated by the white arrow is surrounded by the cracks, while the other indicated by the black arrow is surrounded by both the crack and the sample boundary.

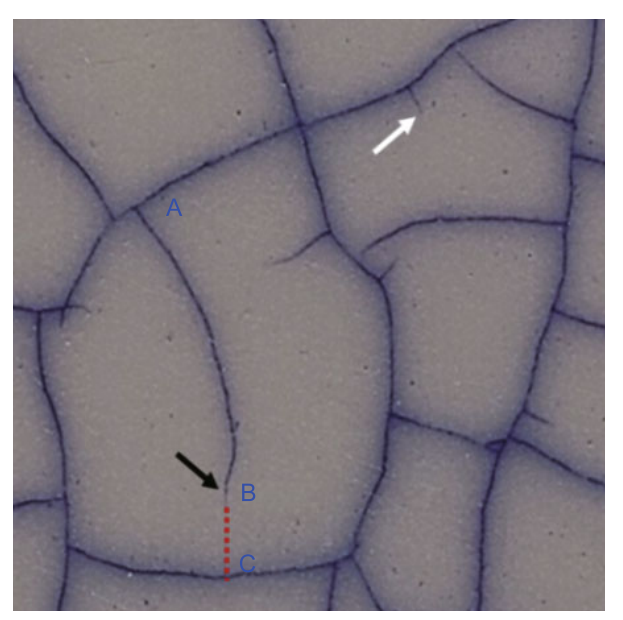

Figure 8 (Color online) Disposal method of dangling crack. The crack indicated by the black arrow will be retained, while the crack indicated by the white arrow will be removed. 
the whole scope, the number of crack units is ensured about 500. The crack unit density on the cooled surface and the crack density on the cut surface are shown in Figures 6(b) and (c), respectively. In all of the statistical analysis, at least five statistic samples are required at each quench temperature.

\section{Results and discussions}

The reticular cracks on the cooled surface develop from uniform thick cracks to a hierarchical structure for thick and fine cracks (Figure 2), which corresponds to the cracks on the cut surface developing from uniform long cracks to a hierarchical structure for long and short cracks (Figures 4, 5 and 6(a)). The crack unit density as a function of the quench temperature is divided into four stages, i.e., a slow increase, a rapid increase, a fast increase and a constant state (Figure 6(b)), while the density of the long and short cracks characterize this evolution in detail (Figure 6(c)).

In the first stage, i.e., $T_{\mathrm{c}} \leqslant T<280^{\circ} \mathrm{C}$, the reticular cracks are composed of thick cracks whose thickness is uniform, and the cracks on the cut surface are almost at the same level and the crack depth presents a single peak distribution. The long crack depth has the maximum of 0.71 at $T_{\mathrm{c}}$, decreases to the minimum value of 0.45 at $T=240^{\circ} \mathrm{C}$, and then increase gradually with a growth rate of $1.0 \times 10^{-30} \mathrm{C}^{-1}$. The crack unit density on the cooled surface increases gradually at $1.5 \times 10^{-3}$ $\mathrm{cm}^{-2}{ }^{\circ} \mathrm{C}^{-1}$, while the crack density on the cut surface also increases gradually at $0.33 \mathrm{~cm}^{-1}{ }^{\circ} \mathrm{C}^{-1}$. Only sparse cracks appear at $T_{\mathrm{c}}$ and the crack unit density is low, but the size of the crack unit shows large diversity and the variance of the crack-unit area is $1.5 \times 10^{2} \mathrm{~mm}^{2}$. As $T$ increases to $280^{\circ} \mathrm{C}$, the variance of the crack-unit area reduces significantly $\left(5.4 \times 10^{-2}\right.$ $\mathrm{mm}^{2}$ ) which indicates that the crack-unit size tends to be unvaried. The long crack depth reaches the maximum value at the critical temperature point and decreases with increasing quench temperature. It might be because the unstable cracking play a key role near the critical temperature point and its role became smaller with increasing quench temperature. As the quench temperature further increases, the unstable cracking can be neglected, and the crack depth increases due to the increasing thermal stress. These experimental results indicate that the reticular cracks develop from thick, deep and sparse, then thinner, shallower and denser, to thicker, deeper and denser with an increase of the quench temperature.

In the second stage, i.e., $280^{\circ} \mathrm{C} \leqslant T<300^{\circ} \mathrm{C}$, the reticular cracks are composed of thick and thin cracks which correspond to the hierarchical structure of long and short cracks on the cut surface. The crack depths on the cut surface present double peaks distribution. Both the depths of the long and short cracks increase, while the growth rate of the long crack depth maintain the value as stage I and is about 6.3 times that of the short crack depth. That is to say, the thickness grading of the reticular cracks is intensified with increasing $T$. The crack-unit density on the cooled surface increases rapidly with a growth rate of $6.0 \times 10^{-2} \mathrm{~cm}^{-2}{ }^{\circ} \mathrm{C}^{-1}$ that is 40 times larger than that in stage $\mathrm{I}$, and the variance of the crack-unit area is almost the same as that in the late part of stage I. Correspondingly, both the densities of the long and short cracks on the cut surface increase. The short crack density increases rapidly with a growth rate of $2.5 \mathrm{~cm}^{-1}{ }^{\circ} \mathrm{C}^{-1}$, which is about 7.6 times that of the long cracks density that maintained the value as stage I. Thus, the rapid increase of reticular crack-unit density is result from the forming of thin cracks. The increase of the thickness of thick cracks and the number of thin cracks are the two major characteristics of the reticular cracks in such stage.

In the third stage, i.e., $300^{\circ} \mathrm{C} \leqslant T<600^{\circ} \mathrm{C}$, the degree of thickness grading of the reticular cracks increases. Both the depth of the long and short cracks on the cut surface respectively increases with the same growth rate as the second stage as the $T$ increased to $500^{\circ} \mathrm{C}$, while these cracks intersect with each other and almost cover the entire sample section as $T$ is higher than $500^{\circ} \mathrm{C}$. The crack unit density on the cooled surface increased fast with a growth rate of $6.4 \times 10^{-3} \mathrm{~cm}^{-2}{ }^{\circ} \mathrm{C}^{-1}$ that is about one-tenth the value at stage II, while the variance keeps the same level as compared with that at stage II. Correspondingly, on the cut surface, the long crack density remains unchanged while the short crack density decreases before a constant period. This indicated that some fine reticular cracks on the cooled surface do not extend to the interior of the ceramic plate.

In the fourth stage, i.e., $600^{\circ} \mathrm{C} \leqslant T \leqslant 800^{\circ} \mathrm{C}$, though both the crack-unit density and the variance almost remain constant, the degree of thickness grading of the reticular cracks further intensified which is reflected by the intersection of the cut surface is strengthened.

Generally, as the quench temperature increase, both the density and the intersection degree of the cracks on the cut surface increase, and the thickness grading degree of the reticular crack on the cooled surface also intensifies. The network structure of the reticular crack is composed of thick and deep cracks, which becomes significant, within which the thin and shallow cracks are intersected with each other.

\section{Summary}

The thermal shock cracks of the ceramic plate show the typical characteristics of reticular-shaped cracking. Quench temperature has a significant effect on the characteristics of the reticular crack. Crack unit density on the cooled surface, the depth and density of the crack on the cut surface are adopted to be quantitatively characterized by the density and thickness grading of the reticular crack. At a low quench temperature, the reticular cracks are composed of thick and deep cracks 
with nearly unvaried thickness. The thickness and depth of the reticular cracks would gradually decrease as the quench temperature increases, accompanied by the increasing of the crack unit density and significant decreasing of the diversity of crack unit size. At a high quench temperature, thickness grading appears in the reticular cracks. The degree of thickness grading would be significantly intensified with increasing quench temperature. The network structure is then composed of thick and deep cracks as skeleton and other thin and shallow cracks intersecting with each other.

The Ge Kiln porcelain, one of the major kilns in the Song Dynasty, is well known for the diversified exquisite cracks on the glaze. As we known, the glaze-crack shape is treated as a critical criterion for the evaluation of the value of ancient ceramics. It is thermal shock that gives ancient ceramics aesthetically pleasing imperfections. Noticeably, the quench temperature has a significant impact on the patterns of the thermal shock cracks, and the reticular crack on the ceramic plate (Figure 2) is strikingly similar to the glaze cracks of the Ge Kiln porcelain (Figure 9). In detail, (1) as the quench temperature is slightly higher than the critical thermal shock temperature, sparse, thick and deep reticular cracks with almost uniform thickness and highly dispersive crack unit size appear (Figure 2(b)). The glaze of brush pot exhibits similar crack characteristics and presents typical "big piece on small porcelain" (Figure 9(a)). (2) As the quench temperature is $40^{\circ} \mathrm{C}-80^{\circ} \mathrm{C}$ higher than $T_{\mathrm{c}}$, the reticular cracks are still composed of thick and deep cracks with uniform thickness, but

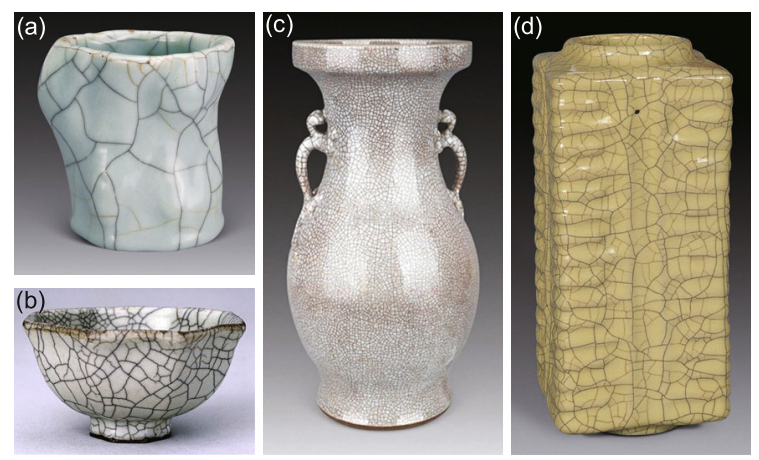

Figure 9 (Color online) Ge Kilns. (a) Brush pot; (b) octagonal bowl; (c) double-ear porcelain vase; (d) yellow glazed square vase. (a) and (b) show large cracks appearing on the smaller ceramics, (c) shows typical uniform small cracks appearing on larger ceramics, and (d) shows ice crack. smaller crack unit size and its dispersion (Figures 2(c)-(e)). The glaze of octagonal bowl exhibits similar crack characteristics (Figure 9(b)). (3) In a $T$ range from $90^{\circ} \mathrm{C}$ to $200^{\circ} \mathrm{C}$, that is higher than $T_{\mathrm{c}}$, thickness grading appears in the reticular cracks, the crack unit density increases rapidly, and both the crack unit size and its dispersion are (Figures 2(f)-(h)). The glaze of the double-ear porcelain vases exhibits similar crack characteristics and shows typical "small piece on big porcelain" (Figure 9(c)). (4) As the quench temperature is much higher than $T_{\mathrm{c}}$, the degree of the thickness grading of the reticular crack becomes significant (Figures 2(i)-(1)). The thick and deep cracks form a framework in which thin and shallow cracks are connected with each other. The glaze of the yellow glazed square vases exhibits similar crack characteristics and shows the ice crack that is constituted by thick and deep cracks, and thin and shallow cracks in a network connection manner (Figure 9(d)).

This work was supported by the National Natural Science Foundation of China (Grant No. 11272313).

1 R. Danzer, T. Lube, P. Supancic, and R. Damani, Adv. Eng. Mater. 10, 275 (2008).

2 B. Wang, and J. Han, Sci. China-Phys. Mech. Astron. 55, 493 (2012).

3 W. D. Kingery, J. Am. Ceram. Soc. 38, 3 (1955).

4 A. Gardel, C. Proisy, S. Lesourd, S. Philippe, J. Caillaud, S. Gontharet, E. J. Anthony, and L. Brutier, J. Coast. Res. 25, 424 (2009).

5 K. Bakos, A. Dombi, F. Jarai-Szabo, and Z. Neda, AIP Conf. Proc. 1564, 205 (2013).

6 S. Nag, S. Sinha, S. Sadhukhan, T. Dutta, and S. Tarafdar, J. Phys. Condens. Matter. 22, 015402 (2010).

7 T. Ishii, and M. Matsushita, J. Phys. Soc. Jpn. 61, 3474 (1992).

8 J. Li, A. K. Dozier, Y. Li, F. Yang, and Y. T. Cheng, J. Electrochem. Soc. 158, A689 (2011).

9 S. Kumar, and A. C. F. Cocks, J. Mech. Phys. Solids. 60, 723 (2012).

10 S. B. Weber, T. Grande, G. W. Scherer, and M. A. Einarsrud, J. Am. Ceram. Soc. 96, 420 (2013).

11 S. Bohn, L. Pauchard, and Y. Couder, Phys. Rev. E 71, 100 (2005).

12 W. Korneta, S. K. Mendiratta, and J. Menteiro, Phys. Rev. E 57, 3142 (1998).

13 K. Leung, and Z. Neda, Phys. Rev. Lett. 85, 662 (2000).

14 Y. W. Wang, B. Xia, H. Su, H. Chen, and X. Feng, Sci. China Technol. Sci. published online.

15 Y. W. Wang, H. L. Yu, H. X. Tang, and X. Feng, Chin. Phys. Lett. 31, 094601 (2014).

16 X. H. Xu, C. Tian, S. L. Sheng, Z. K. Lin, and F. Song, Sci. ChinaPhys. Mech. Astron. 57, 2205 (2014).

17 R. Sokal, and C. Michener, Univ. Kans. Sci. Bull. 38, 1409 (1958). 